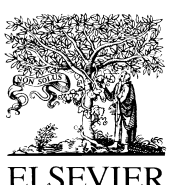

\title{
Modeling swelling soils for disposal barriers
}

\author{
V. Navarro ${ }^{\text {a,* }}$, E.E. Alonso ${ }^{b}$ \\ ${ }^{a}$ Civil Engineering School, University of La Coruña, Campus de Elviña, 15192 La Coruña, Spain \\ ${ }^{\mathrm{b} C i v i l ~ E n g i n e e r i n g ~ S c h o o l, ~ T e c h n i c a l ~ U n i v e r s i t y ~ o f ~ C a t a l u n y a, ~ G r a n ~ C a p i t a n, ~ M o ́ d u l o ~ D-2, ~} 08034$ \\ Barcelona, Spain
}

Received 30 June 1999; received in revised form 5 January 2000; accepted 17 January 2000

\begin{abstract}
A fully coupled advanced formulation for heat, liquid and gas transfer in unsaturated deforming soils is presented. Balance equations are rooted in the theory of mixtures. A double porosity model, which is believed to be especially relevant when simulating expansive soils, is proposed to characterize the water transfer mechanism. Another relevant feature of the framework developed, is the incorporation of a consistent elastoplastic model to describe stressstrain relationships in unsaturated soils. A flexible FE computer program was developed, including an array of alternative numerical strategies and constitutive equations to enhance its capabilities. The experimental results of a hydration and heating experiment performed on confined expansive bentonite were satisfactorily compared with model simulations. (C) 2000 Elsevier Science Ltd. All rights reserved.
\end{abstract}

\section{Introduction}

Highly swelling soils are currently considered to be a suitable barrier for the isolation of waste from the surrounding media. In several design concepts developed by nuclear waste agencies in Europe, Japan and North America waste canisters are placed in a deep gallery or vertical shaft. The annular space between the metallic container and the host rock is then filled with swelling clay. Most of the designs accept the fact that the groundwater will eventually saturate the clay barrier. In this way, a barrier capable of absorbing nuclear radionuclides and impervious to water transfer will isolate the waste. In addition the thermal isolation provided by the clay barrier would also reduce the thermal load imposed on the geological media. In

\footnotetext{
* Corresponding author. Tel.: + 34-981-167000; fax: + 34-981-167170.

E-mail address: vnavarro@iccp.udc.es (V. Navarro).
} 
other applications clay liners are used simply as impervious stable barriers with very low permeability.

The most complex cases (isolation of nuclear waste) require the joint consideration of thermal, hydraulic and mechanical (THM) effects. In fact, nuclear wastes generate heat and induce a temperature gradient around them. If the barrier is unsaturated, which is usually the case after installation, significant vapor transfer takes place in the buffer clay as a result of temperature gradients. Local hydration of the barrier (in contact with the host medium) and drying (close to the heat generating waste) modify the transport coefficients and induce swelling or shrinkage strains. In short, a proper analysis of the barrier requires a coupled thermo-hydro-mechanical approach.

Research on this wide-ranging topic has been intense worldwide over the past two decades. This paper follows a line of research carried out by a number of researchers linked to the Geotechnical Engineering Department of UPC and described in a number of papers [1-9] which deal with the development of constitutive equations for unsaturated soils and the solution of coupled phenomena. This paper presents a rigorous and advanced formulation of the THM processes expected in an expansive clay buffer. A double microstructure is proposed for the expansive clay in order to obtain a more appropriate characterization of its long-term behavior. The experimental evidence for the description of an expansive soil has been discussed in Gens and Alonso [10].

The theoretical basis for the THM model is presented. A brief discussion of its numerical implementation and the main characteristics of the code developed (FADES: Flow And Deformation in Soils) are also outlined. The capabilities of the model are illustrated through the numerical simulation of a small scale laboratory experiment performed by CIEMAT (Centro de Investigación y Experimentación de Materiales) within the scope of a research program sponsored by ENRESA (Empresa Nacional de Residuos SA, Madrid) (Villar et al. [11,12]). In the CIEMAT experiment, samples of compacted bentonite from Almería (a material initially selected by ENRESA as a potential buffer for deep underground disposal) were subjected to simultaneous hydration and heating in an instrumented steel cell. The problem should be considered as a time boundary value problem and, in fact, the test results offered spatial and temporal distributions of several variables: temperature, water content, swelling pressure.

\section{Basic formulation}

According to the ideas presented in Alonso et al. [13] and Gens and Alonso [10], a double structure model is proposed to describe the complex nature of an expansive clay. Clay platelets are packed in aggregates which largely act as silt or sand particles. The pores inside these aggregates are most likely saturated with water which does not flow in the classical Darcy sense. It may, therefore, be considered as a part of the solid phase. Free water and dissolved air partially occupies the larger pores between clay aggregates. Dry air and water vapor occupy the voids. These larger 
pores or accessible voids are referred to here as the macrostructure of the soil. Fig. 1 presents a schematic representation of the soil and the associated phase diagram.

\subsection{Balance equations}

In order to develop a mathematical formulation of the model the theory of mixtures (Truesdell and Toupin [14]) was selected as a suitable framework. This theory provides an opportunity to revise and discuss the relative importance and significance of different terms in a systematic way. The general expressions initially derived here were later applied to the specific soil model selected.

\subsubsection{Water mass balance}

Water mass balance is expressed by the equation (Navarro [15]):

$$
\frac{D_{\mathrm{s}} m^{\mathrm{w}}}{D t}+m^{\mathrm{w}} \nabla \cdot \mathbf{v}^{s}+\nabla \cdot\left(\rho^{\mathrm{w}} \mathbf{q}^{\mathrm{w}}\right)=0
$$

where:

$$
m^{\mathrm{w}}=\rho^{\mathrm{w}} \theta^{\mathrm{w}}=\rho^{\mathrm{wL}} n S r+\rho^{\mathrm{v}} n(1-S r)+\rho^{\mathrm{m}} w
$$

$m^{\mathrm{w}}$ is the apparent water density (mass per unit of total volume), $\rho^{\mathrm{w}}$ is the average water density, $\theta^{\mathrm{w}}$ is the average volumetric content of water, $\rho^{\mathrm{wL}}$ is the density of free water, $n$ is the macrostructure porosity, $S r$ is its degree of saturation, $\rho^{\mathrm{v}}$ is the vapor density, $\rho^{\mathrm{m}}$ is the microstructural water density and $w$ is the micro porosity (see also Fig. 1). The total water mass flow rate was obtained from the free water flow rate $\mathbf{q}^{\mathrm{L}}$ (vectors are denoted by bold lower case letters) and from the vapor flow rate $\mathbf{q}^{\mathrm{v}}$ :

$$
\rho^{\mathrm{w}} \mathbf{q}^{\mathrm{w}}=\rho^{\mathrm{wL}} \mathbf{q}^{\mathrm{L}}+\rho^{\mathrm{v}} \mathbf{q}^{\mathrm{v}}
$$
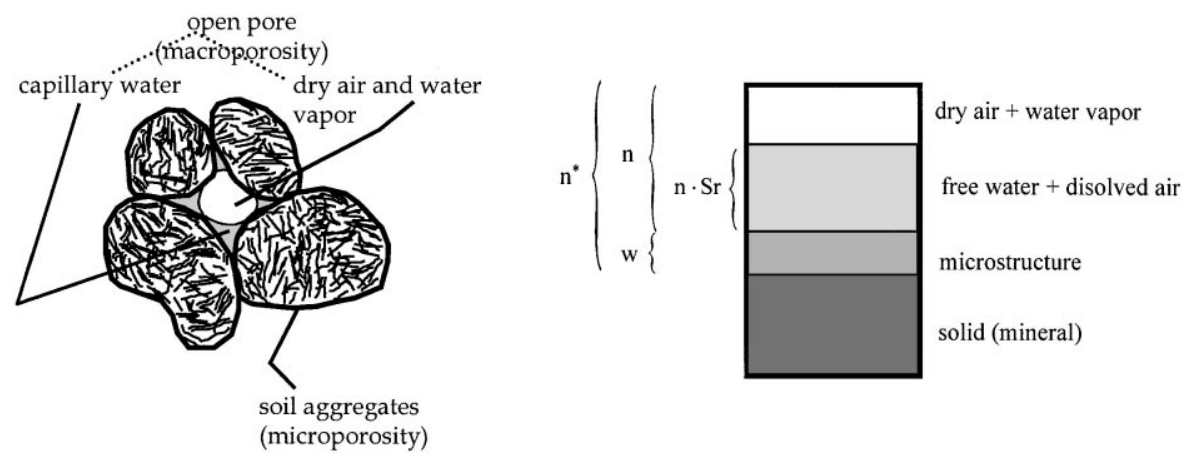

Fig. 1. Schematic representation of the soil structure [13], where: $n^{*}$, total porosity; $n$, macroporosity; $w$, microporosity; $S r$, degree of saturation of the macrostructure. 
The vector $\mathbf{v}^{\mathrm{s}}$ is the velocity of the solid skeleton, therefore, $D_{\mathrm{s}} \mathrm{O} / D t$ defines the material derivative with regard to the movement of solid particles.

\subsubsection{Air mass balance}

Air mass-balance is expressed by the equation:

$$
\frac{D_{\mathrm{s}} m^{\mathrm{a}}}{D t}+m^{\mathrm{a}} \nabla \cdot \mathbf{v}^{\mathrm{s}}+\nabla \cdot\left(\rho^{\mathrm{a}} \mathbf{q}_{\mathrm{TOT}}^{\mathrm{a}}\right)=0
$$

where the average density of air $m^{\mathrm{a}}$ is expressed by:

$$
m^{\mathrm{a}}=\rho^{\mathrm{a}} n(1-\operatorname{Sr}(1-H))
$$

In this equation $\rho^{\mathrm{a}}$ is the air density and $H$ is Henry's constant. The total flow rate of air $\mathbf{q}_{\text {TOT }}^{\mathrm{a}}$ is equal to the flow rate of "free" air (non-dissolved) in gaseous phase $\mathbf{q}^{\mathrm{a}}$ plus the flow rate of dissolved air:

$$
\mathbf{q}_{\text {тот }}^{\mathrm{a}}=H \mathbf{q}^{\mathrm{L}}+\mathbf{q}^{\mathrm{a}}
$$

\subsubsection{Solid mass balance}

The solid mass balance may be expressed similarly:

$$
\frac{D_{\mathrm{s}}}{D t}\left(\rho^{\mathrm{s}}\left(1-n^{*}\right)\right)+\rho^{\mathrm{s}}\left(1-n^{*}\right) \nabla \cdot \mathbf{v}^{\mathrm{s}}=0
$$

where $\rho^{\mathrm{s}}$ is the density of solid particles and $n^{*}$ defines the soil total porosity $\left(n^{*}=n+w\right.$, see Fig. 1). If the coefficient of thermal expansion of solid particles, $C_{\mathrm{T}}^{\mathrm{s}}$, is introduced, the preceding equation could be expressed in the following form:

$$
\frac{D_{\mathrm{s}} n^{*}}{D t}=\left(1-n^{*}\right)\left[-C_{\mathrm{T}}^{\mathrm{s}} \frac{D_{\mathrm{s}} T}{D t}+\nabla \cdot \mathbf{v}^{\mathrm{s}}\right]
$$

where the particle's mechanical compressibility, $C_{\mathrm{P}}^{\mathrm{s}}$, is disregarded $\left(C_{\mathrm{T}}^{\mathrm{s}}>>C_{\mathrm{p}}^{\mathrm{s}}\right)$.

\subsection{Energy balance}

Local thermal equilibrium between the soil constituents is assumed. Therefore, the temperature is postulated to be constant for all phases and species. Hence, only one equation of internal energy is needed. The internal energy balance has been defined by means of the enthalpy balance:

$$
\frac{D_{\mathrm{s}} h}{D t}+h \nabla \cdot \mathbf{v}^{\mathrm{s}}+\nabla \cdot \mathbf{l}^{\mathrm{e}}=0
$$


Term $h$ represents the average specific enthalpy of soil:

$$
\begin{aligned}
\mathrm{h}= & \rho^{\mathrm{wL}} n S r h^{\mathrm{wL}}+\rho^{\mathrm{m}} w h^{\mathrm{m}}+\rho^{\mathrm{v}} n(1-S r) h^{\mathrm{v}}+\rho^{\mathrm{a}} n(1-S r(1-H)) h^{\mathrm{a}} \\
& +\rho^{\mathrm{s}}(1-(n+w)) h^{\mathrm{s}}
\end{aligned}
$$

where $h^{\mathrm{wL}}, h^{\mathrm{m}}, h^{\mathrm{v}}, h^{\mathrm{a}}$ and $h^{\mathrm{s}}$ are the specific enthalpies of free water, micro water, vapor, air and solid particles respectively, which are linear functions of temperature:

$$
\begin{aligned}
& h^{\mathrm{wL}}=c_{\mathrm{p}}^{\mathrm{wL}}\left(T-T_{\mathrm{o}}\right) \\
& h^{\mathrm{v}}=c_{\mathrm{p}}^{\mathrm{v}}\left(T-T_{\mathrm{o}}\right)+h_{\mathrm{o}}^{\mathrm{v}} \\
& h^{\mathrm{m}}=c_{\mathrm{p}}^{\mathrm{m}}\left(T-T_{\mathrm{o}}\right)+h_{\mathrm{o}}^{\mathrm{m}} \\
& h^{\mathrm{s}}=c_{\mathrm{p}}^{\mathrm{s}}\left(T-T_{\mathrm{o}}\right)
\end{aligned}
$$

Specific heats at constant pressure, $c_{\mathrm{p}}^{O}(O: \mathrm{wL}, \mathrm{v}, \mathrm{m}$ and $\mathrm{s})$, are assumed to be constant; $h_{o}^{\mathrm{v}}$ is the specific enthalpy of water vapor at temperature $T_{\mathrm{o}}$, and $h_{o}^{\mathrm{m}}$ is the specific enthalpy of micro water (amount of heat released per mass unit of macro water that becomes micro water) at the same temperature.

\subsection{Equilibrium equation}

In this paper an incremental formulation of the equilibrium equation is used:

$$
\nabla \cdot\left(\Delta \boldsymbol{\sigma}^{*}+\Delta \mathrm{p}^{\mathrm{g}} \cdot \mathbf{m}\right)+\Delta \tilde{n} \cdot g \cdot \mathbf{k}=0
$$

where $\Delta \rho$ is the change in average soil density, $g$ is the gravitational acceleration, $\mathbf{k}$ is the unit vector in the gravity direction, $\mathbf{m}$ is the vectorial expression of the Kronecker delta, $p^{\mathrm{g}}$ is the gas pressure and $\boldsymbol{\sigma}^{*}$ is the significant stress vector [16-18] which is related to the total stress $\sigma$ by means of the expression:

$$
\boldsymbol{\sigma}^{*}=\boldsymbol{\sigma}-p^{\mathrm{g}} \mathbf{m}
$$

\section{Constitutive equations}

\subsection{Motion equations}

Most authors agree on the use of a generalized Darcy's law in order to model the flow through interconnected (macro) porosity. Heat flow is also modeled as a superposition of conductive flow (Fourier's law) and a series of convective flows which correspond to the existing mass transfer phenomena. However, there are discrepancies when the flow of gas is considered. There are two basic strategies as follows: 
1. Advective/dispersive formulations. The average gas flow is defined by an (advective) Darcy equation. The dispersion of different species around the average flow is described by means of a generalized Fick's law. This is the case of Pollock [19].

2. Purely diffusive formulations. The total flow of species is defined by means of Fick's law. This is the approach followed by Ewen and Thomas [20].

Both formulations started as phenomenological relations and their theoretical and physical validity was not initially questioned [21]. However, Hassanizadeh [22] concludes that advective/dispersive models have a better conceptual foundation than purely dispersive models. Accordingly, in this paper an advective/diffusive model was used for the motion equations.

Water flow (macro) was calculated by:

$$
\mathbf{q}^{\mathrm{L}}=-\frac{\kappa^{\mathrm{L}} \underline{\mathbf{K}}^{\mathrm{L}}}{\mu^{\mathrm{wL}}} \cdot\left(\nabla p^{\mathrm{L}}-\rho^{\mathrm{wL}} g \mathbf{k}\right)
$$

where $p^{\mathrm{L}}$ is the liquid pressure, $\kappa^{\mathrm{L}}$ is the relative permeability of macro water, $\underline{\mathbf{K}}^{\mathrm{L}}$ is its intrinsic permeability (matrices are shown in bold print with underlined capital letters) and $\mu^{\mathrm{wL}}$ is its dynamic viscosity. In the preceding equation the viscosity of the liquid phase was identified with the viscosity of macro water, i.e. the effect of dissolved air in the mean liquid flow was disregarded. The program includes several empirical laws for both intrinsic and relative permeability.

The advective flow rate of gas is defined by the equation:

$$
\mathbf{q}^{\mathrm{g}}=-\frac{\kappa^{\mathrm{g}} \underline{\mathbf{K}}^{\mathrm{g}}}{\mu^{\mathrm{g}}} \cdot\left(\nabla p^{\mathrm{g}}-\rho^{\mathrm{g}} g \mathbf{k}\right)
$$

where $\kappa^{\mathrm{g}}$ and $\underline{\mathbf{K}}^{\mathrm{g}}$ are the relative and the intrinsic permeabilities of gas, respectively. In some research $[23,19] \underline{\mathbf{K}}^{\mathrm{g}}$ is considered to be equal to $\underline{\mathbf{K}}^{\mathrm{L}}$ since it is argued that intrinsic permeability is a unique function of soil porosity and structure. However, the permeability of each phase is linked to the loss of phase momentum [24]. It would, therefore, be reasonable to assume that the intrinsic permeability for liquid and gas phases are not the same. $\mu^{\mathrm{g}}$ is the dynamic viscosity of gas, which may be obtained by means of a volumetric average of dry air and vapor viscosities. The same approach is used to define the average density $\rho^{\mathrm{g}}$. FADES includes different equations to define the intrinsic and relative permeability of the gas phase. A common approach is to derive these expressions through the equation proposed by Yoshimi and Osterberg [25] to define gas permeability. If the gas pressure is low, or if the size of pores is small (similar to the mean free path of gas molecules), the gas flow rate will be higher than expected because the average velocity of gas in the solid-gas interface is not zero. This phenomenon is called the Klinkenberg or Knudsen effect [23]. Scheidegger [26] has reviewed several corrections to take this phenomenon into account. In this paper, however, these corrections were not used.

An advective/diffusive formulation was used to calculate the vapor flow rate: 


$$
\rho^{\mathrm{v}} \mathbf{q}^{\mathrm{v}}=\rho^{\mathrm{v}} \mathbf{q}^{\mathrm{g}}+\mathbf{j}^{\mathrm{v}}
$$

where $\mathbf{j}^{\mathrm{v}}$ is the dispersive mass flow of vapor with respect to the average gas flow, calculated by means of Fick's law:

$$
\mathbf{j}^{\mathrm{v}}=-\underline{\mathbf{D}} \cdot \nabla X^{\mathrm{v}}
$$

where $X^{\mathrm{v}}$ is the vapor mass fraction $\left(X^{\mathrm{v}}=\rho^{\mathrm{v}} / \rho^{\mathrm{g}}\right)$ and $\underline{\mathbf{D}}$ is the hydrodynamic dispersion tensor. It includes the effects of both mechanical dispersion $\left(\underline{\mathbf{D}}_{\text {disp }}\right)$ and molecular diffusion $\left(\underline{\mathbf{D}}_{\text {dif }}\right)$ [23]:

$$
\underline{\mathbf{D}}=\underline{\mathbf{D}}_{\mathrm{dif}}+\underline{\mathbf{D}}_{\mathrm{disp}}
$$

Peclet number Pe (defined as $\mathrm{Pe}=\mathrm{V} \cdot \mathrm{D} / D_{\text {dif }}$, where $v$ is the advective flow rate, $d$ is the mean size of the macroporosity and $D_{\text {dif }}$ is the magnitude of the molecular diffusion) was assumed to be less than one for the problems considered in this paper. Thus, the hydrodynamic dispersion can be considered as equal to molecular diffusion [23]. As per Pollock [19]:

$$
\underline{\mathbf{D}}_{\mathrm{dif}}=\rho^{\mathrm{g}} n(1-S r) \tau D \underline{\mathbf{I}}
$$

where $\tau$ is the soil tortuosity, $D$ is the binary diffusion coefficient of water vapor in gas and $\underline{\mathbf{I}}$ is the identity tensor.

Free air flow rate is expressed by:

$$
\rho^{\mathrm{a}} \mathbf{q}^{\mathrm{a}}=\rho^{\mathrm{a}} \mathbf{q}^{\mathrm{g}}+\mathbf{j}^{\mathrm{a}}
$$

where the air dispersion is obtained from the vapor dispersion:

$$
\mathbf{j}^{\mathrm{a}}=-\mathbf{j}^{\mathrm{v}}
$$

Several empirical relations are available in FADES to define the retention curve, all of which relate suction and degree of saturation on a one-to-one basis. No hystheresis effects or incremental formulations [27] were introduced.

Finally, the flow rate of energy $\mathbf{l}^{\mathrm{e}}$ is expressed by the equation:

$$
\mathbf{l}^{\mathrm{e}}=-\underline{\boldsymbol{\Lambda}} \cdot \nabla T+\left(\mathbf{l}^{\mathrm{e}}\right)_{\mathbf{c}}
$$

where $\underline{\boldsymbol{\Lambda}}$ is the thermal conductivity tensor and $\left(\mathbf{l}^{\mathrm{e}}\right)_{\mathrm{c}}$ is the advective energy flow rate:

$$
\left(\mathbf{l}^{\mathrm{e}}\right)_{\mathrm{c}}=\rho^{\mathrm{wL}} h^{\mathrm{wL}} \mathbf{q}^{\mathrm{L}}+\rho^{\mathrm{v}} h^{\mathrm{v}} \mathbf{q}^{\mathrm{v}}+\rho^{\mathrm{a}} h^{\mathrm{a}} \mathbf{q}_{\text {тот }}^{\mathrm{a}}
$$

\subsection{Thermomechanical model}

The program was designed to incorporate the so-called Barcelona Basic Model or BBM [2,5]. The formulation used is more specifically described in Alonso et al. [6]. 
Ledesma et al. [7] developed a numerical procedure to compute the stress increments associated with strain changes, which is the approach used in FADES, with minor changes.

Simpler constitutive equations are also available in the program. These can be useful when the amount and quality of the available soil experiments is limited.

Linear and nonlinear models, as well as the well-known state surface approach $[28,29]$ are available. In these models the mechanical law is defined by the expression:

$$
\mathrm{d} \varepsilon=\underline{\mathbf{C}} \cdot \mathrm{d} \boldsymbol{\sigma}^{*}+\beta \cdot \mathrm{d} s+\boldsymbol{\alpha} \cdot \mathrm{d} T
$$

where $\varepsilon$ is the microstructural strain vector, $\underline{\mathbf{C}}$ is the elastic matrix, $\beta$ defines the effect of suction changes (which depends on the stress state) and $\alpha$ is the vector of thermal expansion coefficients.

The THM formulation described in the above sections is based on a systematic review of the approaches that are widely accepted at the present time, in terms of conceptual models, constitutive equations and the way in which the balance equations are formulated. Despite its unique characteristics, this contribution is not isolated in this wide field. In fact, authors belonging to the same research team have developed CODE-BRIGHT [38], which is also a fully coupled THM finite element program. However, the inclusion of double porosity in the model presented here is an important novel contribution which was a key feature in the development of the FADES program. CODE-BRIGHT was originally oriented towards modeling saline media, while FADES was designed, from the start, as an appropriate tool for simulating the behavior of expansive clays. Due to this difference in conception it was considered advisable for the two codes to be developed in parallel. They share some common conceptual foundations, but the programming tasks were developed independently. This led to the development of two completely different programs, each having its own structure, implementation and numerical algorithms. Appendix 1 gives a brief description of FADES main numerical characteristics. Model capabilities will be illustrated in the next section.

\section{Simulation of a coupled thermomechanical test}

Villar et al. [11,12] have described in detail several experimental set-ups aimed at obtaining information on the behavior of compacted bentonite subjected to the type of thermal and hydraulic changes expected in a clay buffer. Test number 8 was simulated through a fully coupled analysis. Compacted bentonite was placed in a cylindrical stainless steel cell with an inner diameter of $15.0 \mathrm{~cm}$, an inner height of $15.6 \mathrm{~cm}$ and a thickness of $3.6 \mathrm{~cm}$. A central heater, which did not penetrate fully the clay (height $10.0 \mathrm{~cm}$ ), created a temperature gradient in horizontal and vertical directions. The bentonite was wetted through the lower end. Fig. 2 is a diagram showing the test set up and the boundary conditions.

The rate of heat loss through the boundary, $q^{*}$, was defined as a "spring" type of condition according to (Thomas, [30] and Navarro, [15]): 


$$
q^{*}=\lambda \cdot\left(T_{i}-T_{\mathrm{REF}}\right)
$$

where $T_{i}$ is the boundary temperature of the bentonite in ${ }^{\circ} \mathrm{C}, T_{\mathrm{REF}}$ is the reference temperature outside the cell (assumed to be almost constant and equal to $20^{\circ} \mathrm{C}$ ), and the heat transfer coefficient $\lambda$, was considered to be equal to $8 \mathrm{~J}\left({ }^{\circ} \mathrm{C}\right)^{-1} \mathrm{~m}^{-2} \mathrm{~s}^{-1}$. According the test plan, temperature was increased in the heater from an initial value of $20^{\circ} \mathrm{C}$ to a final value of $96.5^{\circ} \mathrm{C}$ during the first $30 \mathrm{~min}$ of the experiment. This temperature increase was assumed to be linear. Thereafter temperature was fixed during the test duration $(2401.6 \mathrm{~h})$. The water pressure was increased at the base to a constant value of $1100 \mathrm{kPa}$.

Initial conditions for the compacted bentonite are given in Table 1.

The retention curve (see Fig. 3) was derived by fitting the hyperbolic law proposed by Lloret [18] to the experimental data provided by the UPC [32]. The following expression was obtained:

$$
S r=0.95-0.6 \tanh \left(0.94 \times 10^{-5} \cdot s\right)
$$

where suction $s$ is expressed in $\mathrm{kPa}$. From Eq. (26) the initial suction for $S r_{\mathrm{o}}$ equal to 0.49 is found to be $s_{\mathrm{o}}=106546 \mathrm{kPa}$. Therefore, if the initial gas pressure was $p_{\mathrm{o}}^{\mathrm{g}}=$ $100 \mathrm{kPa}$, the initial liquid pressure is calculated as $p_{\mathrm{o}}^{\mathrm{L}}=-106446 \mathrm{kPa}$.

To take the thermal effects into account, the exponential-void ratio dependent law of permeability proposed by Lloret [18] was modified, introducing a new factor function of the temperature. Based on the UPC's [32] experimental data the bestfitting curve for total permeability, $k^{\mathrm{L}}(\mathrm{m} / \mathrm{s})$, was obtained:

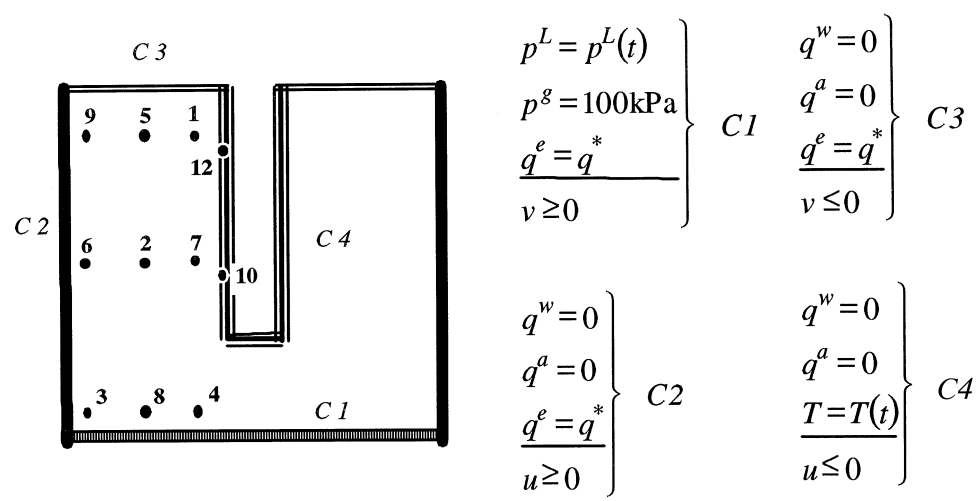

Fig. 2. Test scheme and boundary conditions: $q$, heat flow; $u$, horizontal displacement; $v$, vertical displacement. Enumerated dots, thermocouples position.

Table 1

Bentonite parameters after compaction (CIEMAT [31])

\begin{tabular}{llll}
\hline$\rho_{\mathrm{d}, \mathrm{o}}\left(\mathrm{g} / \mathrm{cm}^{3}\right)$ & $w_{\mathrm{o}}(\%)$ & $S r_{\mathrm{o}}(\%)$ & $n_{\mathrm{o}}$ \\
\hline 1.66 & 11.8 & 49 & 0.40 \\
\hline
\end{tabular}




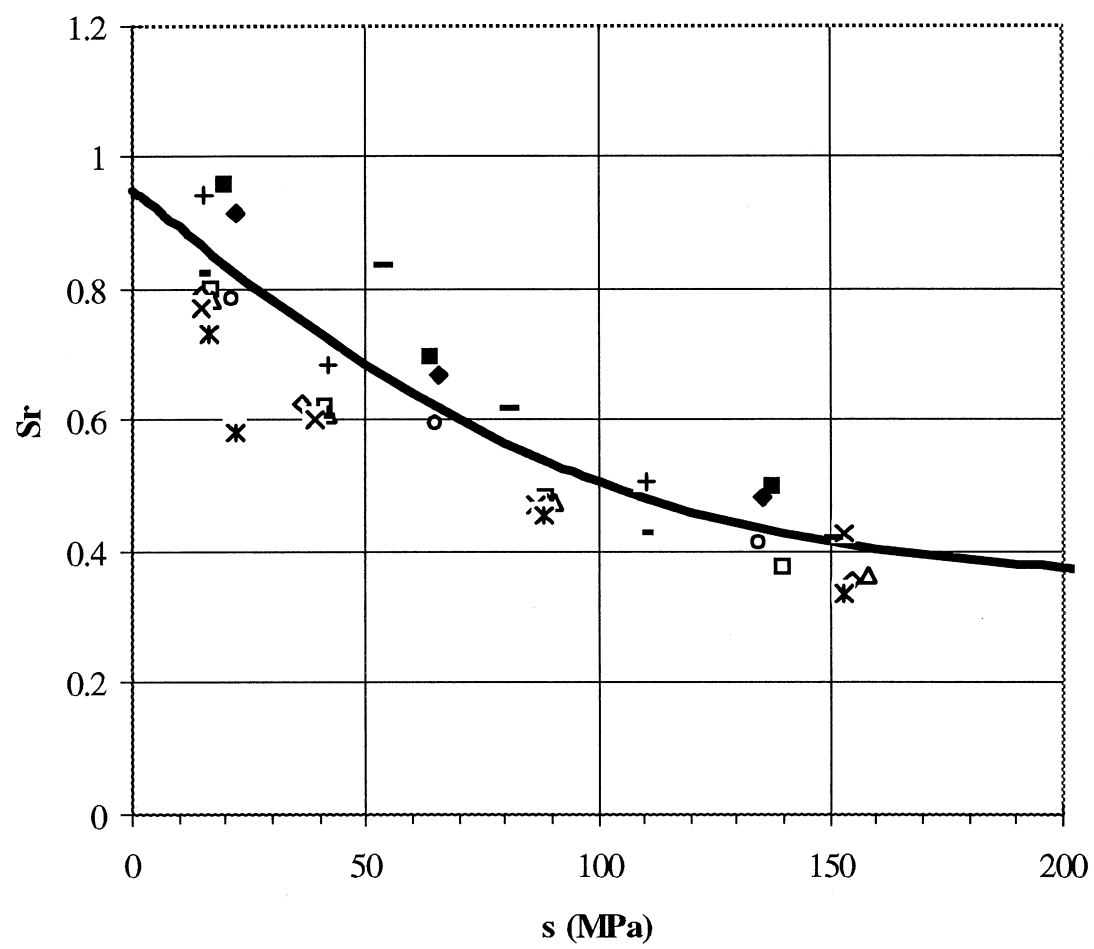

Fig. 3. Retention curve: $S r$, degree of saturation; s: suction. Dots: UPC [32] experimental results. Line: model.

$$
k^{\mathrm{L}}=3.6 \times 10^{-17} \cdot \exp (0.017 \cdot T) \cdot 10^{5 e}
$$

where $T$ is the temperature $\left({ }^{\circ} \mathrm{C}\right)$ and $e$ is the void ratio. Therefore, provided that the liquid dynamic viscosity was defined by means of (Ewen and Thomas [20]):

$$
\mu^{\mathrm{wL}}=661.2 \times 10^{-3} \cdot(T-20)^{-1.562}\left(T:{ }^{\circ} \mathrm{C} ; \mu^{\mathrm{wL}}: \mathrm{N} \cdot \mathrm{s} \cdot \mathrm{m}^{-2}\right)
$$

the intrinsic permeability of liquid was described by the equation:

$$
K^{\mathrm{L}}=3.6 \times 10^{-21} \frac{\exp (0.017 \cdot T)}{(T+44.15)^{1.562}} 10^{5 e}\left(K^{\mathrm{L}}: \mathrm{m}^{2}\right)
$$

Due to the lack of experimental data, Irmay's cubic law [33] was used to define the relative permeability of liquid:

$$
\kappa^{\mathrm{L}}=\left(\frac{S r-0.05}{0.95}\right)^{3}
$$




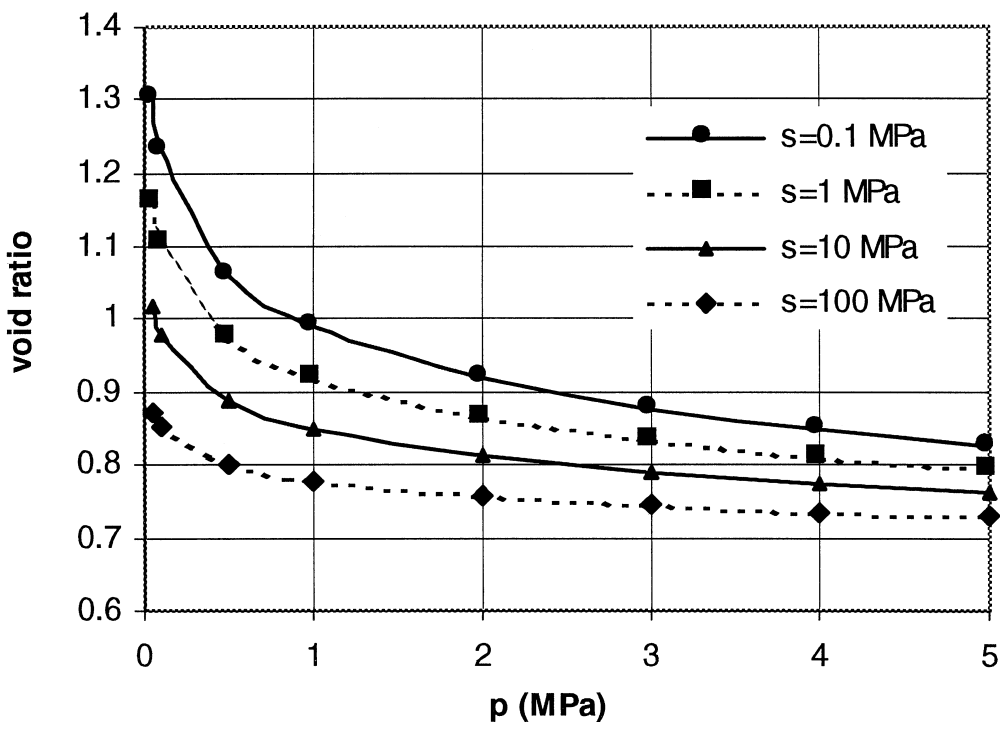

Fig. 4. Void ratio state surface: $p$, net mean stress; $s$, suction.

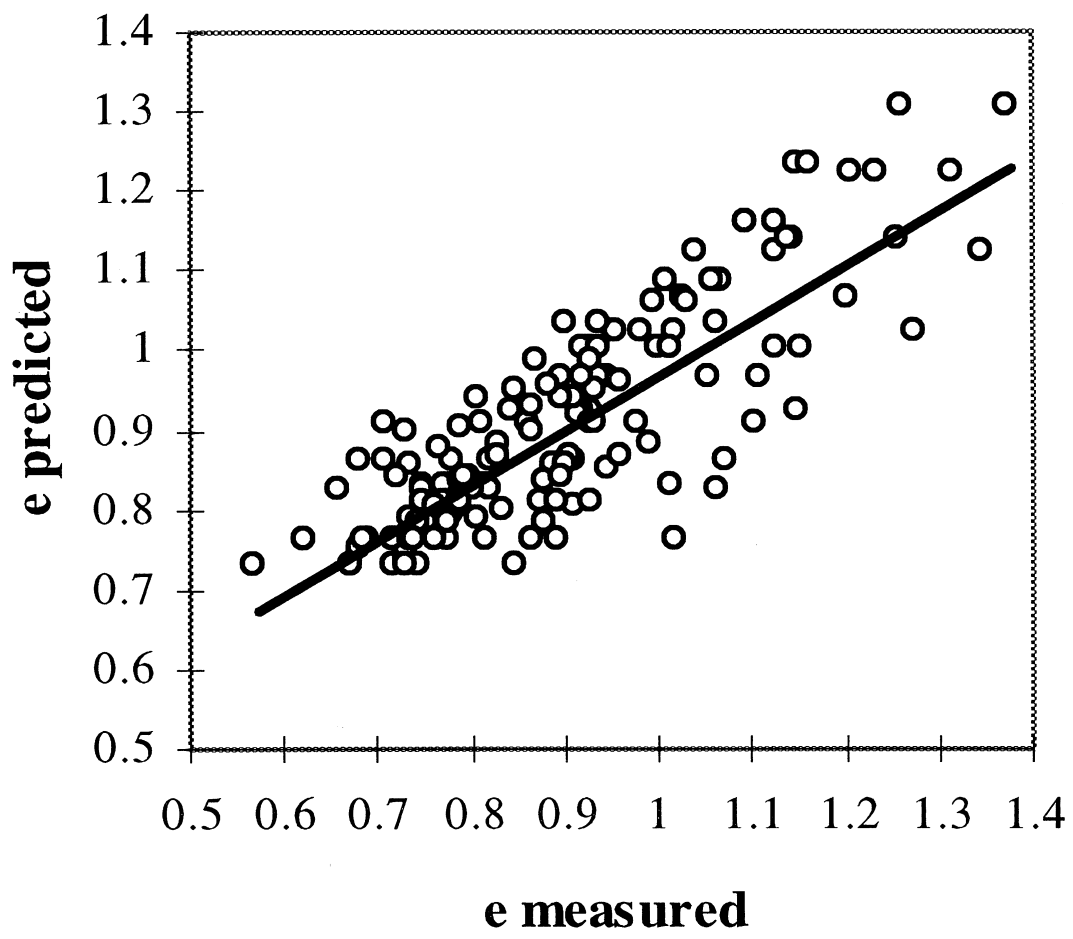

Fig. 5. Correlation between measured and predicted void ratios. 
where the parameters are consistent with those adopted by Villar et al. [11] to define the total permeability.

Gas permeability was modeled according to the Yoshimi and Osterberg [25] expression. Parameters were derived from the expressions provided by Thomas and He [34]:

$$
\begin{aligned}
& K^{\mathrm{g}}=10^{-12} \times e^{4} \\
& \kappa^{\mathrm{g}}=(1-S r)^{4}
\end{aligned}
$$

Volumetric deformations were described by means of a state surface for the void ratio (Fig. 4). Its parameters were obtained by fitting experimental data published by CIEMAT [31] and UPC [32]. The resulting equation is:

$$
\begin{aligned}
e= & 1.88068-0.35056 \cdot \log p-0.22753 \cdot \log (s+1) \\
& +0.05565 \cdot \log p \cdot \log (s+1)(s, p: \mathrm{kPa})
\end{aligned}
$$

where $p$ is the net mean stress. Fig. 5 shows the correlation between measured and predicted void ratios. The correlation coefficient is 0.6872 .

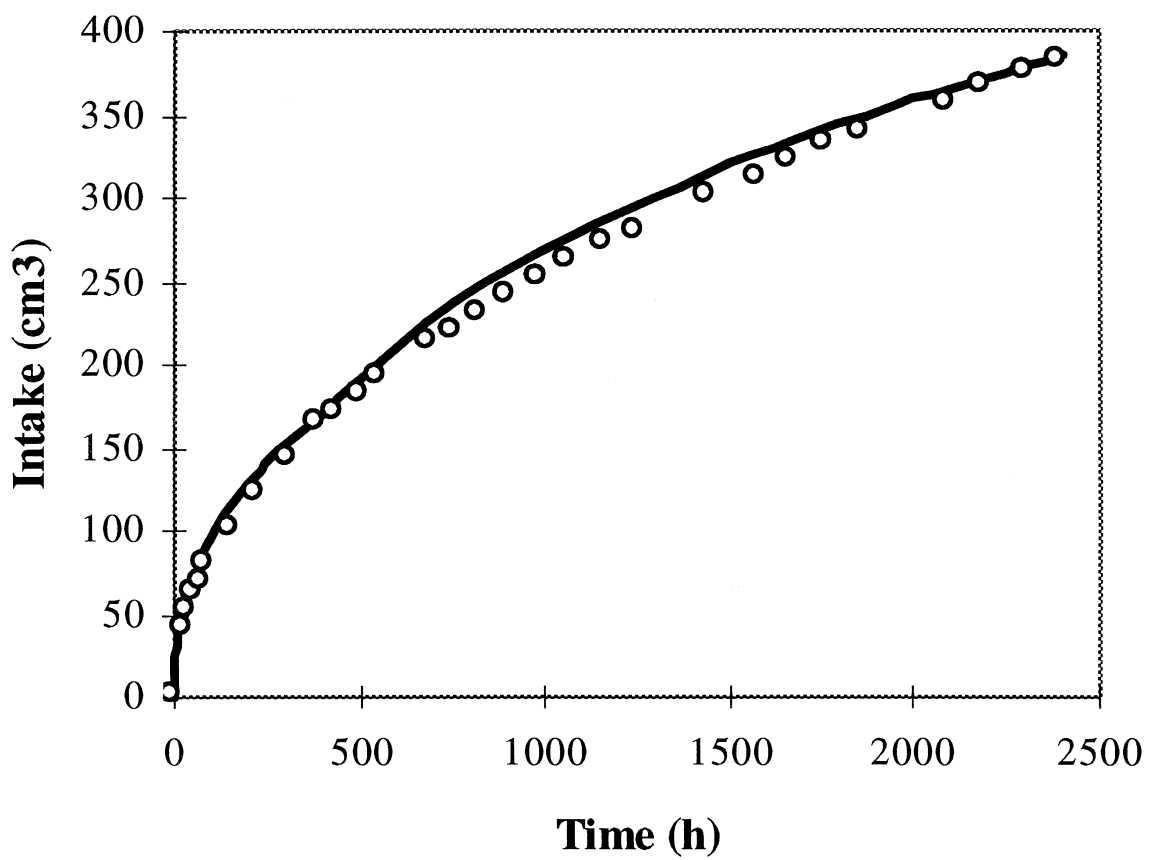

Fig. 6. Water intake evolution. Dots, measured values (CIEMAT [31]). Line, FADES's computed values. 
A nonlinear thermoelastic model describes the mechanical behavior of the compacted bentonite [see Eq. (24)]. The elastic matrix $\underline{\mathbf{C}}$ and vector $\boldsymbol{\beta}$ were obtained by the differentiation of Eq. (32) and by means of a constant Poisson's ratio $v=0.33$. A thermal expansion coefficient, $\alpha=2.6 \times 10^{-4}{ }^{\circ} \mathrm{C}^{-1}$, was derived from UPC [2] experimental data.

The test symmetry allows an axisymmetric analysis. The domain occupied by the bentonite was discretized by a mesh of 154 elements. Linear rectangles were used for elements associated with the flow of gas, liquid and temperature. Quadratic elements were used in connection with displacements. Spatial integration was performed through a Gauss quadrature with nine points per element. A Crank-Nicolson scheme was used for the time integration.

A comparison of the variables measured and model calculation is given in Figs. 611. The prediction of flow rate over time is excellent, as seen in Fig. 6. A reasonable

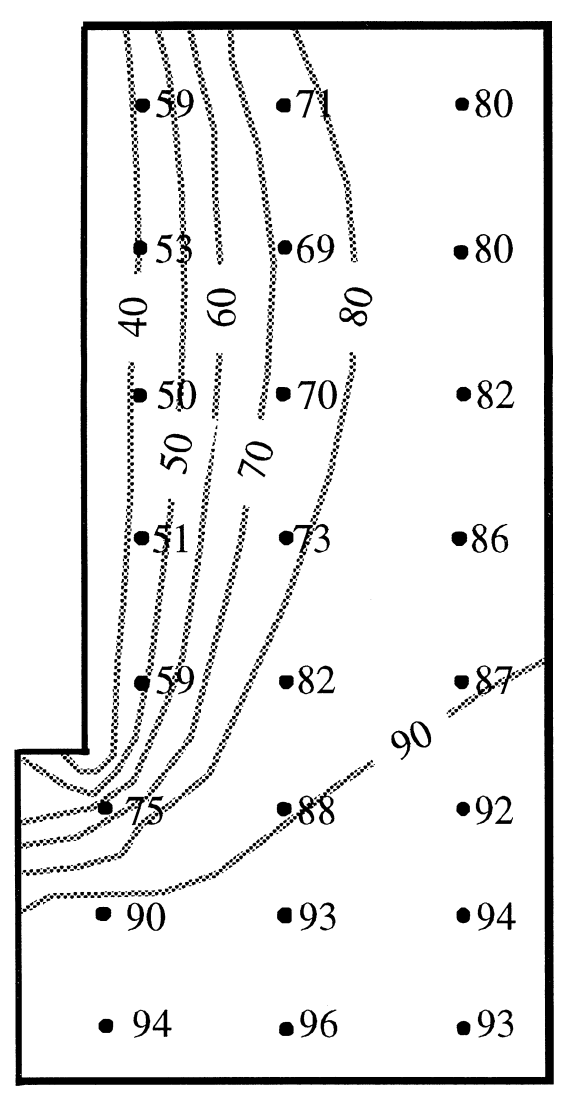

Fig. 7. Distribution of degree of saturation (\%) at the end of the simulation $(2401.6 \mathrm{~h})$. Dots: measured values; lines: numerical results. 


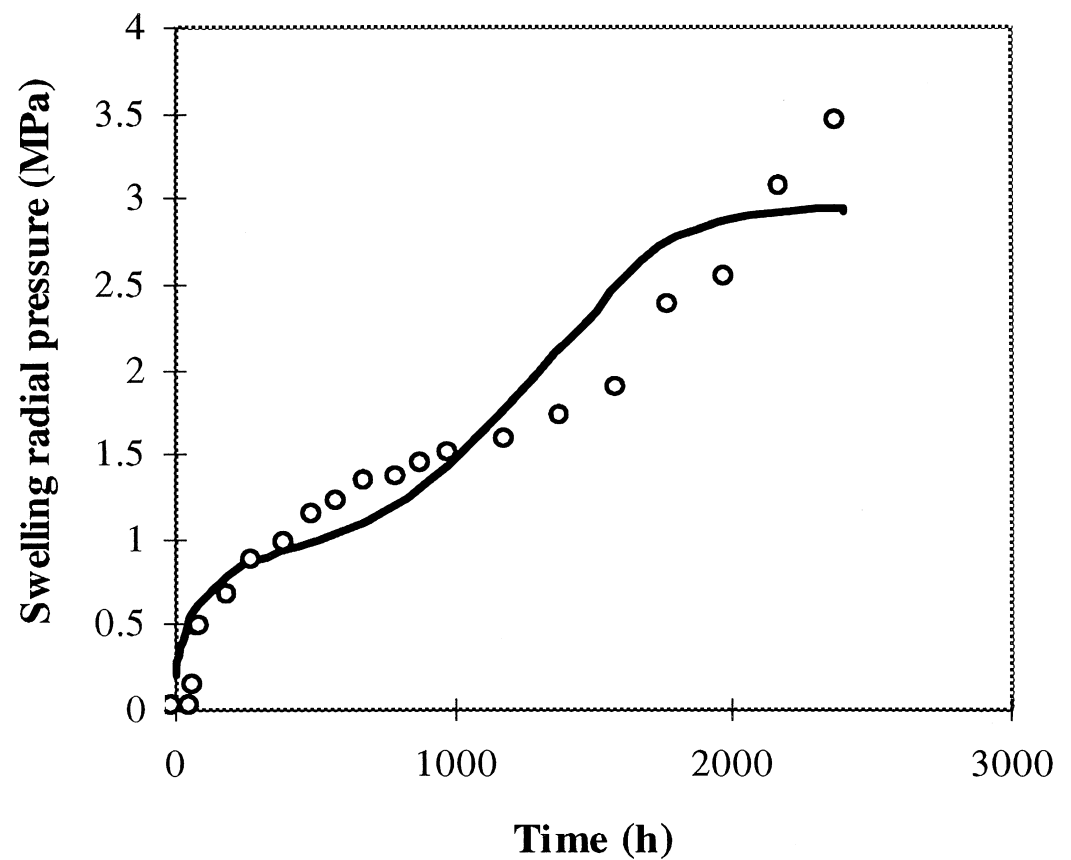

Fig. 8. Radial pressure evolution during the experience (on the wall of the cell, $1 \mathrm{~cm}$ over the bottom plate). Dots measured values (CIEMAT [32]). Line, FADES's results.

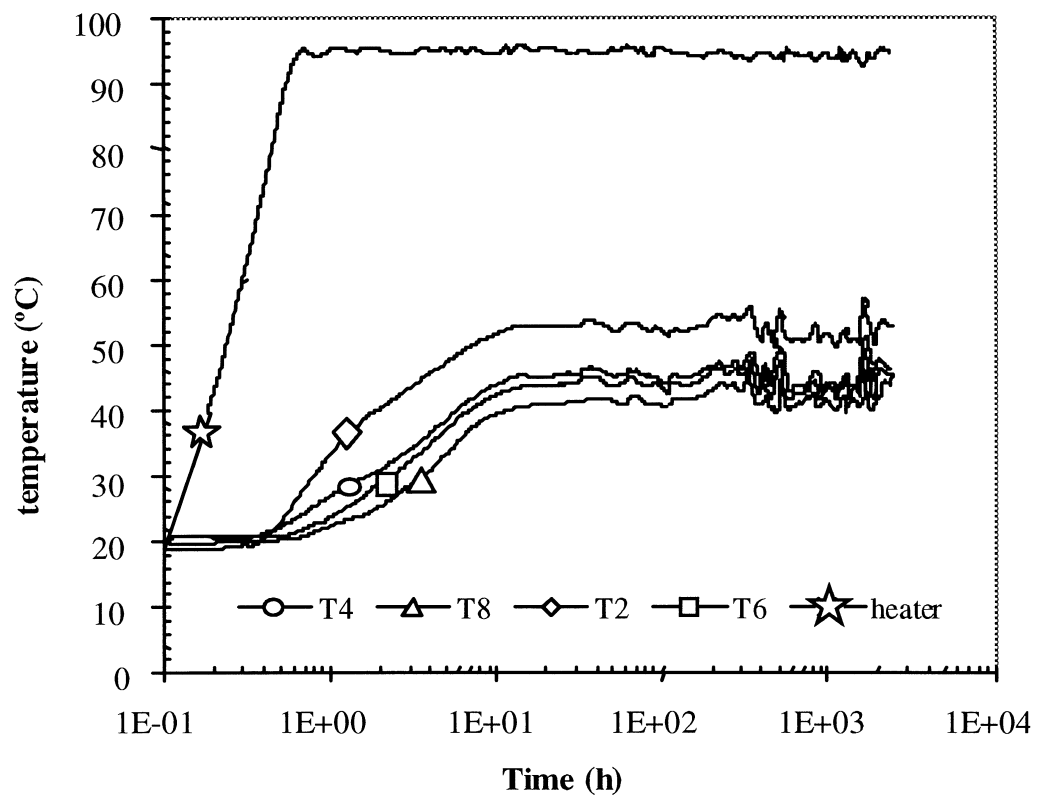

Fig. 9. Temperature evolution during the experience at different thermocouples. Measured values. 
approximation for the distribution of the degree of saturation at the end of the test was also computed (Fig. 7). However, the predicted values near the heater were lower than the values actually measured. Experimental results were obtained, in this case, when the cell was dismantled and cooled. This process is believed to modify the actual values found at the end of the experiment.

Swelling radial pressure was measured in a transducer located on the cell wall, 1 $\mathrm{cm}$ high over the bottom plate. Computed results are very sensitive to the soil stiffness against suction or net stress changes. Nevertheless, model predictions capture the actual measurements with acceptable accuracy (Fig. 8).

Temperature distribution was accurately predicted as indicated by Figs. 9 and 10 . The temperature history of five thermocouples was selected for this comparison. The short-range temperature variations observed in the data measured were probably due to daily changes in room temperature (a constant value $T=20^{\circ} \mathrm{C}$ was taken for the analysis). The temperature remained stationary after the first $20 \mathrm{~h}$ from the beginning of the test.

Isotherms computed at $25.6 \mathrm{~h}$ after the start of the test are compared in Fig. 11 with the values measured. They generally coincided, with the main discrepancies being found in the vicinity of the lower and upper boundaries, especially in close proximity to the heater for the second location. Heat dissipation through the upper and lower plates may require an improved modeling.

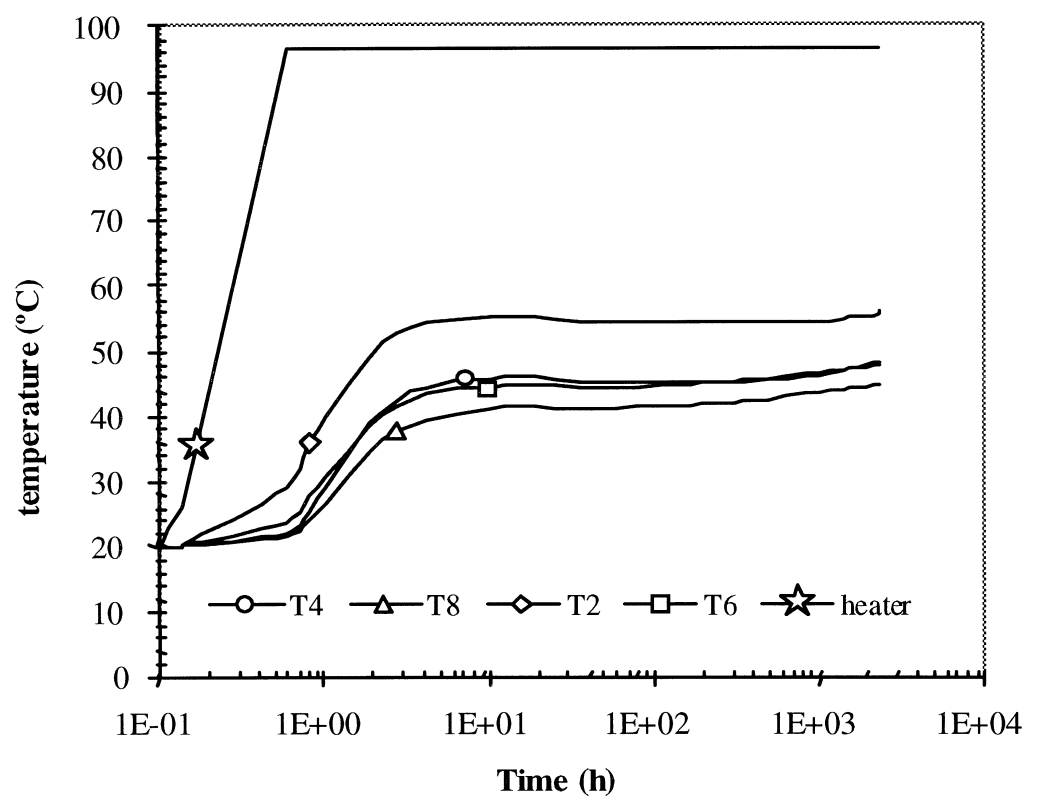

Fig. 10. Temperature evolution during the experience at different thermocouples. Computed results. 


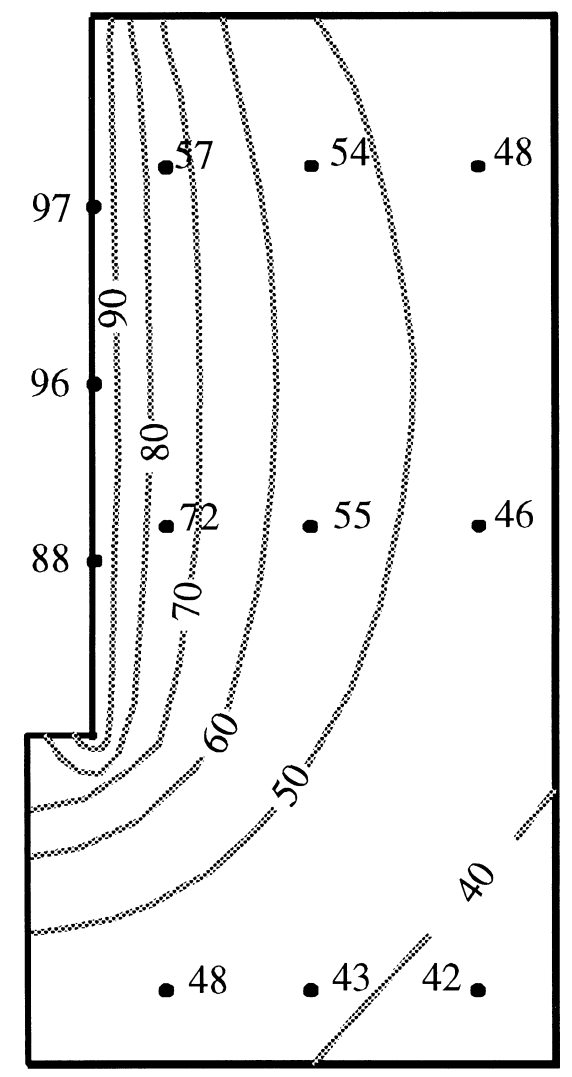

Fig. 11. Temperature distribution after $25.6 \mathrm{~h}$ (points: experimental values; lines: computed results).

\section{Conclusions}

The paper has presented a comprehensive formulation for coupled thermo-hydromechanical phenomena in unsaturated soils. The model is especially suitable for expansive soils whose properties are better interpreted if due consideration is given to the soil microstructure. The model includes a double structure formulation for fluid transfer that is integrated into the general framework of a balance and equilibrium relationship.

A flexible computer program (FADES) was designed. Mathematical details of the numerical solution of the governing equations have also been included. FADES is an efficient tool which uses alternative numerical strategies and a number of different constitutive equations for the different physical phenomena considered. The user may thus select the most appropriate analysis.

An elastoplastic model (BBM: Barcelona Basic Model) consistently describes the stress-strain relationship of unsaturated soils. Simpler options are also available.

A hydration and heating experiment on compacted bentonite, confined in a rigid cell, was simulated in order to demonstrate the capabilities of the formulation. Soil 
parameters were derived from a comprehensive set of experiments. A general agreement was found to exist between the variables measured and the model calculations.

\section{Acknowledgements}

This research was financed in part by a Research Grant awarded to the first author by the Education Department of the Catalunya Local Government. Thanks are also given to CIEMAT for granting permission to use their experimental results to validate the model developed.

\section{Appendix 1: Numerical implementation}

A brief summary of the main numerical features of the FADES program is given here. More information is available in Navarro [15].

\section{A.1.1. Spatial discretization}

A finite element discretization procedure was applied to the system of differential equations defined above. Spatial discretization of balance and equilibrium equations follows the Bubnov-Galerkin procedure. Flow Eqs. (1), (4) and (9) have the same structure:

$$
\frac{D_{\mathrm{s}} m}{D t}+m \nabla \cdot \mathbf{v}^{\mathrm{s}}+\nabla \cdot \mathbf{l}=0
$$

where the "generalized mass" $m$ is $m^{\mathrm{w}}$ in Eq. (1), $m^{\mathrm{a}}$ in Eq. (4) and $h$ in Eq. (9). On the other hand, the "generalized mass flow rate" $\mathbf{l}$ is $\rho^{\mathrm{w}} \mathbf{q}^{\mathrm{w}}, \rho^{\mathrm{a}} \mathbf{q}_{\text {TOT }}^{\mathrm{a}}$ and $\mathbf{l}^{\mathrm{e}}$ respectively in Eqs. (1), (4) and (9). This common structure has allowed us to use the same numerical treatment for the three equations, and, therefore, an important optimization of the code was achieved. For each element, topologically identified as $D^{\mathrm{e}}$, the spatial discretization of flow equations yields the following equation:

$$
\int_{D^{\mathrm{e}}} N_{\mathrm{f}}^{\mathrm{t}} \cdot\left(\frac{D_{\mathrm{s}} m}{D t}+m \nabla \cdot \mathbf{v}^{\mathrm{s}}\right) \mathrm{d} V-\int_{D^{\mathrm{e}}}\left(\nabla^{\mathrm{t}} \mathbf{N}_{\mathrm{f}}\right)^{\mathrm{t}} \cdot \mathbf{l} \mathrm{d} V-\int_{\partial D_{2}^{\mathrm{e}}} \mathbf{N}_{\mathrm{f}}^{\mathrm{t}} \cdot 1^{*} \mathrm{~d} S=0
$$

where $l^{*}$ represents the external inflow of generalized mass and the components of vector $\mathbf{N}_{\mathrm{f}}$ are the shape functions of the flow variables (liquid pressure, gas pressure and temperature). These shape functions may differ from those used to interpolate displacements. This is a technique commonly used to avoid numerical errors when dealing with incompressible materials in undrained problems [35]. Symbol " $t$ " defines the transpose operator.

The assembly of Eq. (34) into the whole domain reads as follows: 


$$
\begin{aligned}
& \underset{\mathrm{e}}{\mathbf{E}}\left\{\int_{D^{\mathrm{e}}}\left(\mathbf{N}_{\mathrm{f}}^{\mathrm{e}}\right)^{\mathrm{t}} \cdot\left(\frac{D_{\mathrm{s}} m}{D t}+m \nabla \cdot \mathbf{v}^{\mathrm{s}}\right) \mathrm{d} V-\int_{D^{\mathrm{e}}}\left(\nabla^{\mathrm{t}} \mathbf{N}_{\mathrm{f}}^{\mathrm{e}}\right)^{\mathrm{t}} \cdot \mathbf{l d} V-\int_{\partial D_{2}^{\mathrm{e}}}\left(\mathbf{N}_{\mathrm{f}}^{\mathrm{e}}\right)^{\mathrm{t}} \cdot 1^{*} \mathrm{~d} S\right\} \\
& \quad=0
\end{aligned}
$$

where $\mathbf{E}$ is the assembly symbol. If the global variation of mass $\mathbf{m m}$ and the external supply of mass $\mathbf{f m}$ are defined as:

$$
\begin{aligned}
& \mathbf{m m}(\mathrm{t})=\underset{\mathrm{e}}{\mathbf{E} m m^{\mathrm{e}}}(t)=\underset{\mathrm{e}}{\mathbf{E}}\left\{\int_{D^{\mathrm{e}}}\left(\mathbf{N}_{\mathrm{f}}^{\mathrm{e}}\right)^{\mathrm{t}} \cdot\left(\frac{D_{\mathrm{s}} m}{D t}+m \nabla \cdot \mathbf{v}^{\mathrm{s}}\right) \mathrm{d} V-\int_{D^{\mathrm{e}}}\left(\nabla^{\mathrm{t}} \mathbf{N}_{\mathrm{f}}^{\mathrm{e}}\right)^{\mathrm{t}} \cdot \mathbf{l} \mathrm{d} V\right\} \\
& \mathbf{f m}(\mathrm{t})=\underset{\mathrm{e}}{\mathbf{E} f m^{\mathrm{e}}}(t)=\underset{\mathrm{e}}{\mathbf{E}} \int_{\partial D_{2}^{e}}\left(\mathbf{N}_{\mathrm{f}}^{\mathrm{e}}\right)^{\mathrm{t}} \cdot 1^{*} \mathrm{~d} S
\end{aligned}
$$

the global mass balance for each time $t$ [Eq. (35)] leads to:

$$
\mathbf{m m}(t)-\mathbf{f m}(t)=0
$$

Analogously, the discretization of the equilibrium equation [Eq. (12)] could be expressed in the following form:

$$
\operatorname{md}(t)-\mathbf{f d}(t)=0
$$

where $\operatorname{md}(t)$ defines the balance of internal forces and $\mathbf{f d}(t)$ is obtained from the external loads:

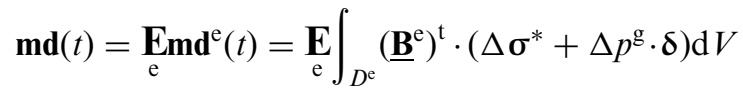

$$
\begin{aligned}
& \mathbf{f d}(t)=\underset{\mathrm{e}}{\mathbf{E} f \mathbf{d}^{\mathrm{e}}}(t)=\underset{\mathrm{e}}{\mathbf{E}} \int_{D^{\mathrm{e}}}\left(\mathbf{N}_{d}^{\mathrm{e}}\right)^{\mathrm{t}} \cdot(\ddot{A} \tilde{n} \mathrm{gk}) \mathrm{d} V+\int_{\partial D_{2}^{\mathrm{e}}}\left(\mathbf{N}_{d}^{\mathrm{e}}\right)^{\mathrm{t}} \cdot \mathbf{t d} S
\end{aligned}
$$

where $\mathbf{N}_{\mathrm{d}}$ is the displacement shape functions and its gradient, $\underline{\mathbf{B}}$, defines the strain shape functions. Thus, the system of equations describing the problem is expressed by:

$$
\mathbf{m}(t)-\mathbf{f}(t)=\left\{\begin{array}{c}
\mathbf{m d}(t)-\mathbf{f d}(t) \\
\mathbf{m m}(t)-\mathbf{f m}(t)
\end{array}\right\}=0
$$

where the vector of mass variations can be split into the "sub-vectors":

$$
\mathbf{m m}(t)=\left\{\begin{array}{c}
\mathbf{m w}(t) \\
\mathbf{m a}(t) \\
\operatorname{me}(t)
\end{array}\right\}
$$

in which $\mathbf{m w}(t)$ is the variation of water mass, $\mathbf{m a}(t)$ is the variation of air mass and $\mathbf{m e}(t)$ is the energy variation. 
The user may specify different types of analysis:

- thermal: $\mathbf{m}(t)=\mathbf{m m}(t)=\mathbf{m e}(t)$.

- flow: $\mathbf{m}(t)=\mathbf{m m}(t)=(\mathbf{m w}(t), \mathbf{m a}(t), \mathbf{m e}(t))$.

- mechanical: $\mathbf{m}(t)=\mathbf{m d}(t)$.

- thermomechanical: $\mathbf{m}(t)=(\mathbf{m d}(t), \mathbf{m e}(t))$.

- saturated isothermal consolidation: $\mathbf{m}(t)=(\mathbf{m d}(t)=, \mathbf{m w}(t))$.

- etc.

Eqs. (40) and (41) are purely formal expressions, since in the program $\mathbf{m}(t)$ is defined as:

$$
\mathbf{m}(t)=\left(\mathbf{m}_{\mathrm{P}_{1}}(t), \ldots, \mathbf{m}_{\mathrm{P}_{\mathrm{nP}}}(t)\right)
$$

Each vector $\mathbf{m}_{\mathrm{Pi}}(t)$ stores the components of $\mathbf{m}(t)$ associated with node $P_{i}(i=1, \ldots n P)$, and:

- if $P_{i}$ is used only to approximate displacements, $\mathbf{m}_{P_{i}}(t)$ includes solely the components of $\mathbf{m d}(t)$ related to $P_{i}: \mathbf{m}_{P_{i}}(t)=\mathbf{m d}_{P_{i}}(t)$.

- if $P_{i}$ is used exclusively in the discretization of flow variables, $\mathbf{m}_{P_{i}}(t)$ includes the components of $\mathbf{m m}(t)$ associated with $P_{i}$. As previously mentioned, $\mathbf{m m}_{P_{i}}(t)$ has different structures which depend on the kind of problem analyzed. It may include the scalars $m w_{P_{i}}(t)$ (water mass variation at node $\left.P_{i}\right), m a_{P_{i}}(t)$ (air mass variation at node $P_{i}$ ) and $m e_{P_{i}}(t)$ (energy variation at node $P_{i}$ ).

- if $P_{i}$ is employed both to approximate displacements and flow variables, $\mathbf{m}_{P_{i}}(t)$ links $\mathbf{m d}_{P_{i}}(t)$ and $\mathbf{m m}_{P_{i}}(t): \mathbf{m}_{P_{i}}(t)=\left(\mathbf{m d}_{P_{i}}(t), \mathbf{m m}_{P_{i}}(t)\right)$.

The vector of the state variables of the problem, $\mathbf{x}(t)$, has the same structure as $\mathbf{m}(t)$ :

$$
\mathbf{x}(t)=\left(\mathbf{x}_{P_{1}}(t), \ldots, \mathbf{x}_{P_{n P}}(t)\right)
$$

where $\mathbf{x}_{P_{i}}(t)$ stores the state variables (liquid pressure, gas pressure, temperature and displacements) associated with $P_{i}$.

In coupled flow-deformation problems, a common scheme for the spatial integration of balance and equilibrium equations is used.

\section{A1.2. Time discretization}

This paper deals with a generalized consolidation problem. Thus, the maximum time derivative order is achieved in the parabolic equations of balance, and is equal to one. Therefore a linear approximation $\mathbf{x}^{*}(t)$ of the state variables $\mathbf{x}(t)$ was used:

$$
\begin{aligned}
& \mathbf{x}^{*}(t)=(1-\mu) \mathbf{x}_{i-1}+\mu \mathbf{x}_{i} \\
& \mu=\frac{t-t_{i-1}}{\Delta_{i} t} ; \Delta_{i} t=t_{i}-t_{i-1} \\
& I_{t}^{i}=\left[t_{i-1}, t_{i}\right] ; I_{t}=\bigcup_{i=1}^{n_{t}} I_{t}^{i}
\end{aligned}
$$


where $I_{t}$ is the time interval analyzed, which is subdivided into $n_{t}$ increments $I_{t}^{i}$. $\mathbf{x}_{i-1}$ is the value of the state variables at the start of increment $i$, and $\mathbf{x}_{i}$ is the value at the end of this increment. In general, the linear approximation of the solution does not satisfy the system of equations defined in Eq. (40), and hence, a residual $\mathbf{r}(t)$ is obtained for each time:

$$
\mathbf{r}(t)=\mathbf{r}\left(\mathbf{x}^{*}(t)\right)=\mathbf{m}\left(\mathbf{x}^{*}(t)\right)-\mathbf{f}\left(\mathbf{x}^{*}(t)\right) \neq 0
$$

The weighting residual, $\mathbf{s}_{i}$, associated with each time increment $I_{t}^{i}$ is expressed by:

$$
s_{i}=\int_{t_{i-1}}^{t_{i}} w(t) \mathbf{r}\left(\mathbf{x}^{*}(t)\right) d t
$$

where $w(t)$ is the weighting function that determines the kind of time discretization used. Since $\mathbf{s}_{i}$ is a function of $\mathbf{r}(t)$, and this vector is in turn a function of $\mathbf{x}_{i}$, the problem will be solved, for each increment, if a vector $\mathbf{x}_{i}$ which satisfies:

$$
\mathbf{s i}\left(\mathbf{x}_{i}\right)=0
$$

is found.

\section{A1.3. Newton-Raphson procedure}

Traditionally (see Alonso et al. [13], for instance) the residual $\mathbf{r}(t)$ is computed at each time by means of the following matrix expression associated with the whole domain:

$$
\left[\begin{array}{cc}
\underline{\mathbf{0}} & \underline{\mathbf{0}} \\
\underline{\mathbf{R}}\left(\mathbf{x}_{i}\right) & \underline{\mathbf{S}}\left(\mathbf{x}_{i}\right)
\end{array}\right]\left\{\begin{array}{c}
\mathbf{x d}^{\prime}{ }_{i} \\
\mathbf{x m}^{\prime}{ }_{i}
\end{array}\right\}+\left[\begin{array}{cc}
\underline{\mathbf{K}}\left(\mathbf{x}_{i}\right) & \underline{\mathbf{Q}}\left(\mathbf{x}_{i}\right) \\
\underline{\mathbf{0}} & \underline{\mathbf{H}}\left(\mathbf{x}_{i}\right)
\end{array}\right]\left\{\begin{array}{c}
\mathbf{x d} \mathbf{d}_{i} \\
\mathbf{x m _ { i }}
\end{array}\right\}=\left\{\begin{array}{c}
\mathbf{f d}\left(\mathbf{x}_{i}\right) \\
\mathbf{f m}\left(\mathbf{x}_{i}\right)
\end{array}\right\}
$$

where $\mathbf{x} \mathbf{d}_{i}$ groups the displacements of the vector $\mathbf{x}_{i}$ and $\mathbf{x m}_{i}$ includes the flow variables. $\mathbf{x} \mathbf{d}_{i}^{\prime}$ and $\mathbf{x m}_{i}^{\prime}$ are the derivatives of the preceding vectors. If a linear variation in time of the state variables is assumed,

$$
\mathbf{x}_{i}^{\prime}=\frac{\mathbf{x}_{i}-\mathbf{x}_{i-1}}{\Delta_{i} t}
$$

Eq. (48) may be written as:

$$
\begin{aligned}
& {\left[\begin{array}{lc}
\underline{\mathbf{K}}\left(\mathbf{x}_{i}\right) & \underline{\mathbf{Q}}\left(\mathbf{x}_{i}\right) \\
\underline{\mathbf{R}}\left(\mathbf{x}_{i}\right) & \underline{\mathbf{S}}\left(\mathbf{x}_{i}\right)+\Delta_{i} t \cdot \underline{\mathbf{H}}\left(\mathbf{x}_{i}\right)
\end{array}\right] \cdot\left\{\begin{array}{c}
\mathbf{x d} \mathbf{d}_{i} \\
\mathbf{x \mathbf { m } _ { i }}
\end{array}\right\}=\underline{\mathbf{G}}\left(\mathbf{x}_{i}\right) \cdot \mathbf{x}_{i}} \\
& \mathbf{f d}\left(\mathbf{x}_{i}\right) \\
& \mathbf{g}\left(\mathbf{x}_{i}\right)=\left\{\begin{array}{c}
\left.\Delta_{i} \mathrm{t} \cdot \mathbf{f m}\left(\mathbf{x}_{i}\right)+\underline{\mathbf{S}}\left(\mathbf{x}_{i}\right) \cdot \mathbf{x} \mathbf{m}_{i-1}+\underline{\mathbf{R}}\left(\mathbf{x}_{i}\right) \cdot \mathbf{x} \mathbf{x}_{i-1}\right) \cdot \mathbf{x}_{i}=\mathbf{g}\left(\mathbf{x}_{i}\right) \Rightarrow \\
\mathbf{s}_{i}\left(\mathbf{x}_{i}\right)=\underline{\mathbf{G}}\left(\mathbf{x}_{i}\right) \cdot \mathbf{x}_{i}-\mathbf{g}\left(\mathbf{x}_{i}\right)=\mathbf{0}
\end{array}\right.
\end{aligned}
$$


It is common to use time integration techniques that involve the evaluation of the submatrices used to obtain $\underline{\mathbf{G}}$ within increment $I_{t}^{i}$. Therefore, in order to solve the system through a Newton-Raphson procedure, the Jacobian matrix $\underline{\mathbf{J}}_{i}$ must be computed:

$$
\underline{\mathbf{J}}_{i}=\frac{\partial \mathbf{s}_{i}}{\partial \mathbf{x}_{i}}=\underline{\mathbf{G}}_{i}+\frac{\partial \underline{\mathbf{G}}_{i}}{\partial \mathbf{x}_{i}} \cdot \mathbf{x}_{i}
$$

To obtain the derivatives of $\underline{\mathbf{G}}$ with respect to the state variables a computational effort is required that is not usually assumed. So it is common to use $\underline{\mathbf{G}}$ as the iteration matrix (i.e. Fixed Point or Picard Scheme). This method has a linear convergence, unlike the quadratic convergence of Newton-Raphson. The latter method was implemented in FADES.

\section{A1.4. Iterative process and resolution skills}

The iterative process carried out to solve each time increment $I_{t}^{i}$ is outlined in Fig. 12. $\mathbf{x}_{i}^{j}$ is the current value of the trial solution of the iteration $j$ and $\Delta \mathbf{x}_{i}^{j}$ is its associated correction, obtained from the linear system:

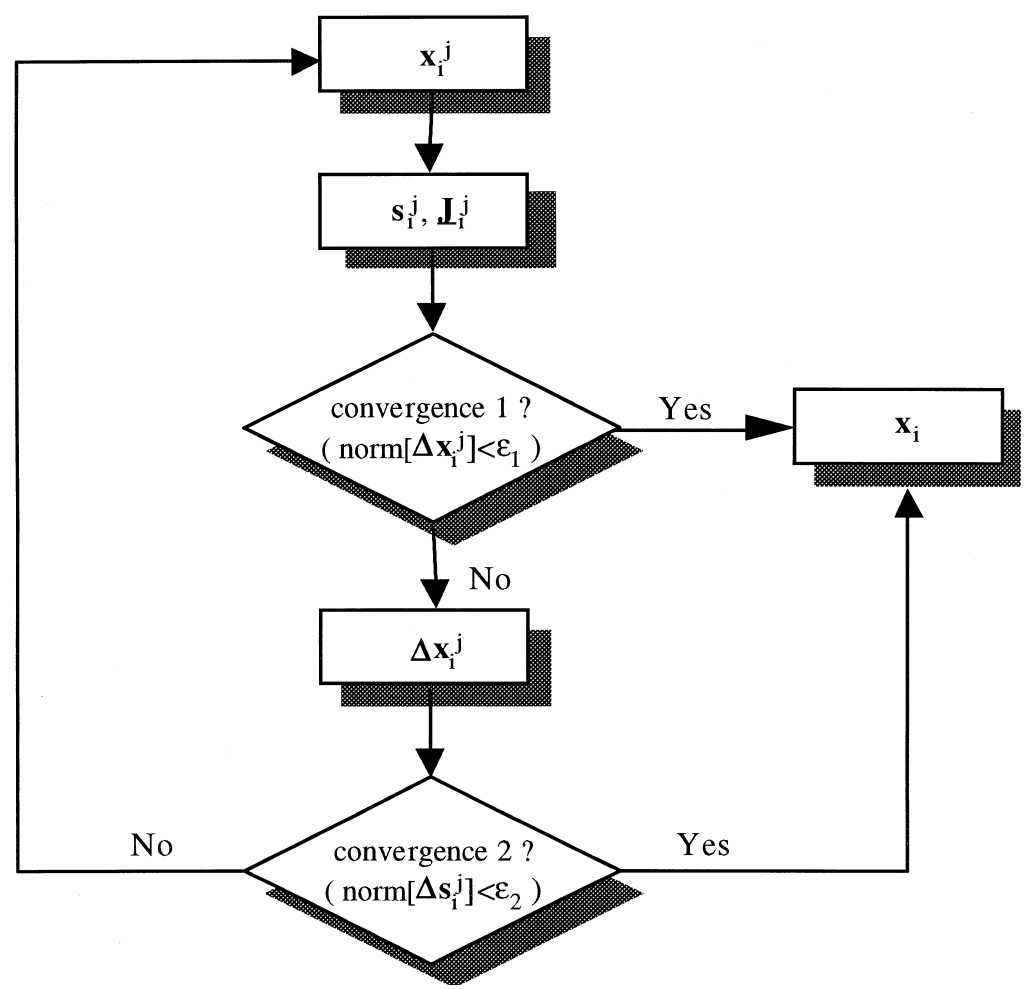

Fig. 12. Outline of the iterative process carried out to solve each time increment. 


$$
\mathbf{s}_{i}^{j+1}=\mathbf{s}_{i}^{j}+\underline{\mathbf{J}}_{i}^{j} \cdot \Delta \mathbf{x}_{i}^{j}=0
$$

where $\mathbf{s}_{i}^{j}$ is the residual associated with $\mathbf{x}_{i}^{j}$, and $\underline{\mathbf{J}}_{i}^{j}$ is the value of the Jacobian matrix. Given $\mathbf{x}_{i}^{j}$, Fig. 13 indicates the procedure to compute $\mathbf{s}_{i}^{j}$ and $\underline{\mathbf{J}}_{i}^{j}$. Vectors $\left(\mathbf{s d}_{i}^{\mathrm{e}}\right)^{j}$ and $\left(\mathbf{s m}_{i}^{\mathrm{e}}\right)^{j}$ are the element residuals derived from the time discretization of Eqs. (36) and (39) in the form:

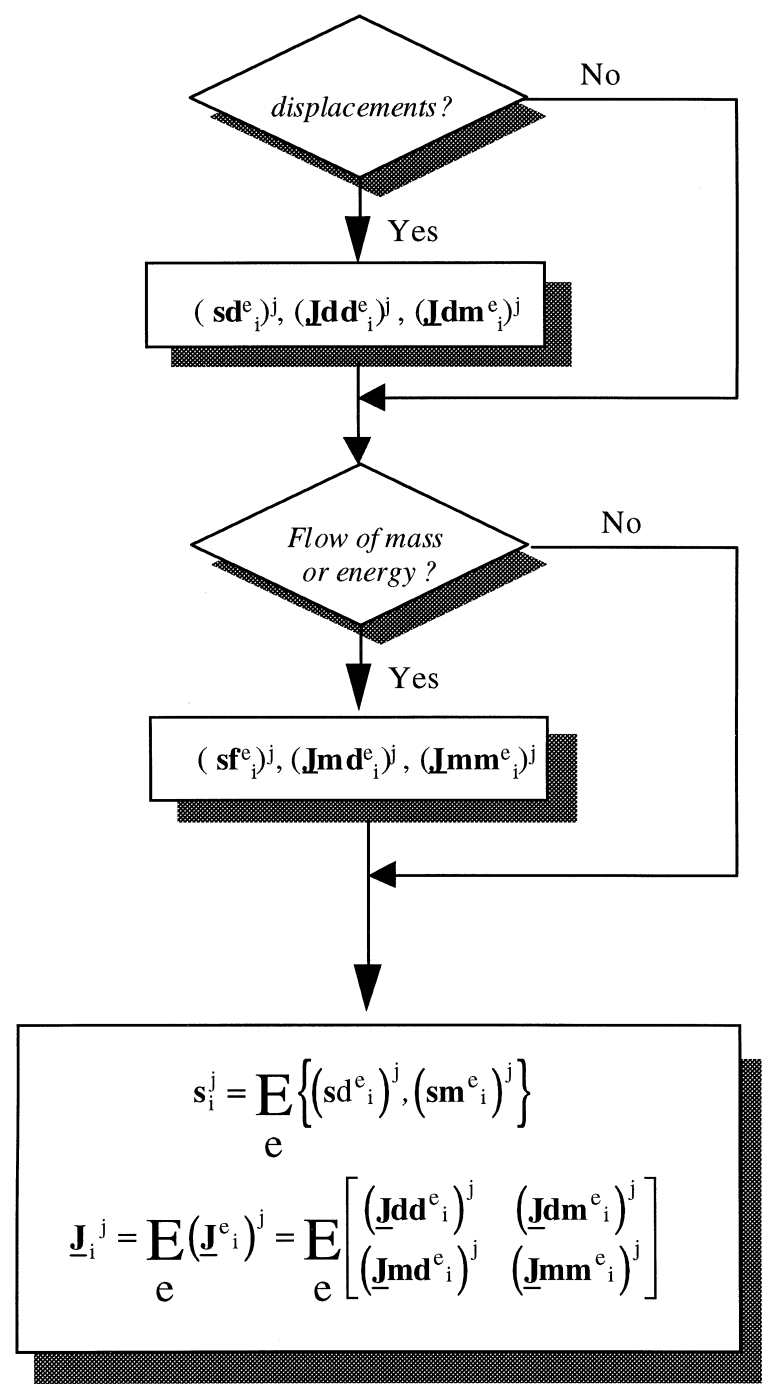

Fig. 13. Computing of the residual and the Jacobian matrix at iteration $j$, increment $i$. 


$$
\begin{aligned}
& \left(\mathbf{s d}_{i}^{\mathrm{e}}\right)^{j}=\int_{t_{i-1}}^{t_{i}} w_{\mathrm{d}}(t) \mathbf{r d}^{\mathrm{e}}\left(\left(\mathbf{x}^{\mathrm{e}}\right)^{*}(t)\right) \mathrm{d} t=\int_{t_{i-1}}^{t_{i}} w_{\mathrm{d}}(t)\left\{\mathbf{m d}^{\mathrm{e}}\left(\left(\mathbf{x}^{\mathrm{e}}\right)^{*}(t)\right)-\mathbf{f d}^{\mathrm{e}}\left(\left(\mathbf{x}^{\mathrm{e}}\right)^{*}(t)\right)\right\} \mathrm{d} t \\
& \left(\mathbf{s m}_{i}^{\mathrm{e}}\right)^{j}=\int_{t_{i-1}}^{t_{i}} w_{\mathrm{m}}(t) \mathbf{r m}^{\mathrm{e}}\left(\left(\mathbf{x}^{\mathrm{e}}\right)^{*}(t)\right) \mathrm{d} t=\int_{t_{i-1}}^{t_{i}} w_{\mathrm{m}}(t)\left\{\mathbf{m m}^{\mathrm{e}}\left(\left(\mathbf{x}^{\mathrm{e}}\right)^{*}(t)\right)-\mathbf{f m}^{\mathrm{e}}\left(\left(\mathbf{x}^{\mathrm{e}}\right)^{*}(t)\right)\right\} \mathrm{d} t
\end{aligned}
$$

The time discretization technique used for the flow equations, $w_{\mathrm{m}}$, may be different from the time discretization approach employed for the equilibrium equation, $w_{\mathrm{d}}$. A total of seven different schemes have been programmed to carry out the time discretization of flow equations. Three of them are mass conservative integrations $[36,37]$ and they provide an exact integration of storage terms over time. Additionally, a total of four time discretization techniques for the equilibrium equation have been included, although the classical implicit scheme is usually selected.

In Eq. (53) $\left(\mathbf{x}^{\mathrm{e}}\right)^{*}(t)$ provides the value of the state variables that are bound to the element. The "element Jacobian matrix" $\left(\underline{\mathbf{J}}_{i}^{\mathrm{e}}\right)^{j}$ is defined in terms of element residuals as:

$$
\begin{aligned}
& \left(\underline{\mathbf{J}}_{i}^{\mathrm{e}}\right)^{j}=\left(\frac{\partial \mathbf{s}_{i}^{\mathrm{e}}}{\partial \mathbf{x}_{i}^{\mathrm{e}}}\right)^{j}=\left(\frac{\partial\left\{\int_{t_{i-1}}^{t_{i}} w(t) \mathbf{r}^{\mathrm{e}}(t) \mathrm{d} t\right\}}{\left.\partial \mathbf{x}_{i}^{\mathrm{e}}\right\}}\right)^{j}
\end{aligned}
$$

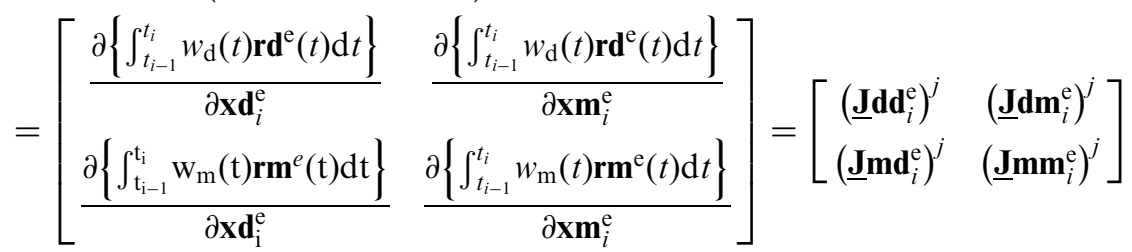

where $\mathbf{x} \mathbf{d}_{i}^{\mathrm{e}}$ and $\mathbf{x m}_{i}^{\mathrm{e}}$ store the element displacements and flow variables respectively. As outlined in Fig. 12, two different convergence criteria are used in the program. If the correction of the state variables has a norm smaller than the tolerance defined by the user, convergence 1 is attained. Alternatively, convergence 2 is achieved if the residual norm is smaller than the accuracy level established by the user. It is possible to force both kinds of convergence to stop the iterative process.

After convergence for each time increment, FADES analyzes the convergence level attained and a new time step is defined accordingly. This automatic generation of time steps allows a substantial saving of CPU time.

In keeping with the storage structure of the state variables, a simultaneous solution of the system of equations or "monolithic" strategy is followed in the program. It has advantages when the physical problems considered are highly coupled. The solver used is based on a Crout decomposition and a nonsymmetrical "sky-line" storage procedure.

The term $m \nabla \cdot \mathbf{v}^{\mathrm{s}}$ in Eq. (33) defines the variation of apparent density as a result of the volumetric deformation of the solid skeleton. The addition of this term to the 
balance equations extends the applicability of a small strain formulation to cases where i) all the elements experience similar deformations (in this way its relative weight in the balance satisfaction across the domain is approximately the same) and ii) there are no significant distortions (so that the weight of the Gauss points does not change significantly).

FADES also takes into account changes of the solution domain geometry during the problem, allowing the consideration of excavation or accumulation (construction phases). Each construction phase is subdivided into steps, and a linear variation of boundary conditions is assumed.

The user selects the times where a converged solution is stored. In this way histories of specified variables are generated. Auxiliary programs perform pre and postprocessor operations. The program has also implemented the "restart" option.

\section{References}

[1] Lloret A, Alonso EE. Consolidation of unsaturated soils including swelling and collapse behaviour. Geotechnique 1980;18(4):449-77.

[2] Alonso EE, Gens A, Hight DW. Special problem soils. General report. Proceedings of the 9th European Conference on Soil Mech Fdn Engng, Dublin 1987;3:1087-146.

[3] Josa A. Un modelo elastoplástico para suelos no saturados. Ph. D. thesis, in Spanish, Universidad Politécnica de Catalunya, 1988.

[4] Alonso EE, Batlle F, Gens A, Lloret A. Consolidation analysis of partially saturated soils. Application to earthdam construction. Proc. 6th Int. Conf. Num. Meth. Geomech., Insbruck 1988: 1303-8.

[5] Gens A, Alonso EE, Josa A. Elastoplastic modelling of partially saturated soils. Proc. 3rd Int. Symp. on Num. Models in Geomech., Niagara Falls 1989, 163-70.

[6] Alonso EE, Gens A, Josa A. A constitutive model for partially saturated soils. Geothecnique 1990;40:405-30.

[7] Ledesma A, Chan AHC, Vaunat J, Gens A. Finite element formulation of an elastoplastic model for partially saturated soils. Proceedings of the 4th International Conference on Computational Plasticity, Barcelona 1995: 1677-88.

[8] Alonso EE, Yang DQ, Lloret A, Gens A. Experimental behaviour of highly expansive double structure clay. Proc 1st Int Conf On Unsaturated Soils, Paris 1995;1:11-16.

[9] Gens A. Constitutive modelling: Application to compacted soils. Unsaturated Clays 1995;3:1179200.

[10] Gens A, Alonso EE. A framework for the behaviour of unsaturated expansive clays. Can Geotech J 1992;29:1013-32.

[11] Villar MV, Cuevas J, Fernández AM, Martin PL. Effects of the interaction of heat and water flow in compacted bentonite. Preliminary results. In: Proceeding of the International Workshop on Thermomechanics of Clays and Clay Barriers, Bergamo, 1993, ISMES.

[12] Villar MV. First results of suction controlled oedometer tets in highly expansive montmorillonite. Proceeding of the 1st International Conference on Unsat Soils, Paris 1995;1:207-22.

[13] Alonso EE, Gens A, Lloret A. Double structure model for the prediction of long-term movements in expansive materials. Proceedings of the 7th International Conference on Comp. Meth and Adv in Geomech, Cairns 1991: 541-548.

[14] Truesdell C, Toupin RA. The classical field theories. Handbuch der Physik, III/1: p. 226-793. Berlin: Springer Verlag, 1960.

[15] Navarro V. Modelo del comportamiento mecánico e hidráulico de suelos no saturados en condiciones no isotermas. Ph. D. thesis, in Spanish, Universidad Politécnica de Catalunya, 1997.

[16] Coleman JD. Stress/strain relations for partly saturated soil. Correspondence to Geotechnique 1962;12(4):348-50. 
[17] Fredlund DG, Morgenstern NR. Stress state variables for unsaturated soils, J. Geotech Engng Div, Am Soc Civ Engrs 1977;5(103):447-66.

[18] Lloret A. Comportamiento deformacional del suelo no saturado bajo condiciones drenadas y no drenadas. Ph. D. thesis, in Spanish, Universidad Politécnica de Catalunya, 1982.

[19] Pollock DW. Simulation of fluid flow and energy transport processes associated with high-level radioactive waste disposal in unsaturated alluvium. Water Resour Res 1986;22(5):765-75.

[20] Ewen J, Thomas HR. Heating unsaturated medium sand. Géotechnique 1989;39(3):455-70.

[21] Hassanizadeh SM. Derivation of basic equations of mass transport in porous media, Part 1. Macroscopic balance laws Adv Water Resour 1986;9:196-206.

[22] Hassanizadeh SM. Derivation of basic equations of mass transport in porous media, Part 2. Generalizated Darcy's and Fick's laws Adv Water Resour 1986;9:207-22.

[23] Bear J. Dynamics of fluids in porous media. New York: American Elsevier, 1972.

[24] Raats PAC. Development of equations describing transport of mass and momentum in porous media, with special reference to soils. Ph. D. thesis, University of Illinois, 1965.

[25] Yoshimi Y, Osterberg JO. Compression of partially saturated cohesive soils. J Soil Mech Fdns Div, Am Soc Civ Engrs 1963;89(4):1-24.

[26] Scheidegger AE. The physics of flow through porous media. 2nd Ed. University of Toronto Press, 1960.

[27] Wheeler SJ. Inclusion of specific water volume within an elasto-plastic model for unsaturated soil. Can Geotech J 1996;33:42-57.

[28] Matyas EL, Radhakrishna HS. Volume change characteristics of partially saturated soils. Géotechnique 1968;18(4):432-48.

[29] Lloret A, Alonso EE. State surfaces for partially saturated soils. Proceedings of the 11th International Conference on Soil Mech Fdn Engng, San Francisco 1985;2:557-62.

[30] Thomas HR. Model development and validation of the thermal-hydraulic-mechanical and geochemical behaviour of the clay barrier. Final report thermo-hydro-mechanical code development and applications. Codes developed at UWCC and their applications CEC Contract FI2W-CT91-0102 (DOEO), 1995.

[31] CIEMAT. Modelling and validation of the thermal-hydraulic-mechanical and geochemical behaviour of the clay barrier. Final report 1991-1994. CEC Contract FI2W-CT91-0102 (DOEO), 1995.

[32] UPC. TMH Laboratory tests in FEBEX phase 3. 70-UPC-L-3-01, Barcelona, 1996.

[33] Irmay S. On the hydraulic conductivity of unsaturated soils. Trans of the Am Geophysical Union 1954;35:463-8.

[34] Thomas HR, He Y. Analysis of coupled heat, moisture and air transfer in a deformable unsaturated soil. Geotechnique 1995;45(4):677-89.

[35] Zienkiewicz OC, Taylor RL. The finite element method, vols. 1 and 2. New York:McGraw-Hill, 1989.

[36] Milly PCD. A mass-conservative procedure for time-stepping in models of unsaturated flow. Adv Water Resour 1985;8:32-6.

[37] Celia MA, Bouloutas ET, Zarba RL. A general Mass-Conservative numerical solution for the unsaturated flow equation. Water Resour Res 1990;26(7):1483-96.

[38] Olivella S, Gens A, Carrera J, Alonso EE. Numerical formulation for the coupled analysis of saline media (CODE-BRIGHT). Engng Comput 1996;13:87-112. 